\title{
Ergonomic Safety and Health Activities to Support Commercial Nuclear Power Plant Control Room Modernization in the United States
}

Jeffrey C. Joe, Casey Kovesdi, Jacques Hugo, Gordon Clefton

August 2018

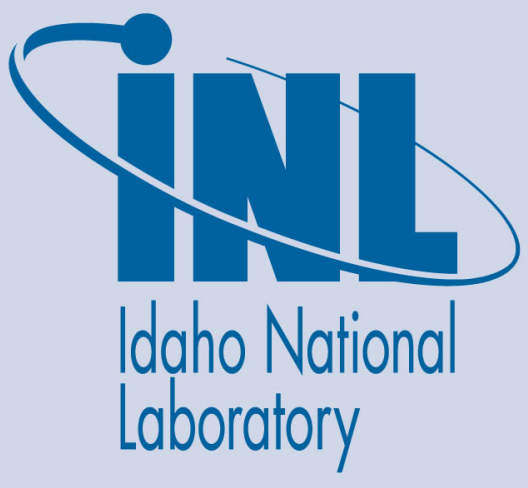

The INL is a U.S. Department of Energy National Laboratory operated by Battelle Energy Alliance 


\title{
Ergonomic Safety and Health Activities to Support Commercial Nuclear Power Plant Control Room Modernization in the United States
}

\author{
Jeffrey C. Joe, Casey Kovesdi, Jacques Hugo, Gordon Clefton
}

\author{
August 2018
}

Idaho National Laboratory Idaho Falls, Idaho 83415

http://www.inl.gov

Prepared for the

U.S. Department of Energy

Under DOE Idaho Operations Office

Contract DE-AC07-05ID14517 


\title{
Ergonomic Safety and Health Activities to Support Commercial Nuclear Power Plant Control Room Modernization in the United States
}

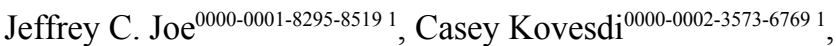 \\ Jacques Hugo ${ }^{0000-0002-3095-27531}$ and Gordon Clefton ${ }^{2}$ \\ ${ }^{1}$ Idaho National Laboratory, Idaho Falls, ID 83415, USA \\ Jeffrey.Joe@inl.gov, Casey.Kovesdi@inl.gov, \\ Jacques. Hugo01@gmail. com \\ ${ }^{2}$ Clefton Enterprises, Swanton, MD 21561, USA \\ gclefton68@gmail.com
}

\begin{abstract}
Affordable, abundant, and reliable electricity generation is essential to fueling a nation's robust and globally competitive economy. In the United States (U.S.), commercial nuclear power plants (NPPs) account for approximately $19 \%$ of reliable and cost-competitive base load electricity generation. Other technologies that reduce reliance on fossil fuels and provide base load electricity cost-competitively at a national scale are still under development. Thus, without suitable replacements for nuclear power, the generating capacity of nuclear energy in the U.S. must be continued through the safe and efficient operation of commercial NPPs. The U.S. Department of Energy's (DOE) Light Water Reactor Sustainability (LWRS) research and development $(\mathrm{R} \& \mathrm{D})$ program provides the technical bases for the long-term, safe, and economical operation of NPPs. One area in the LWRS program is the Plant Modernization pathway, which includes human factors $R \& D$, human factors engineering (HFE), and ergonomics to enable the modernization of the instrumentation and control (I\&C) technologies in NPP main control rooms. DOE researchers, including ergonomics specialists at Idaho National Laboratory (INL), have collaborated with numerous commercial NPP utilities over the last few years on control room modernization. This paper summarizes recent ergonomics safety and health R\&D and HFE performed in collaboration with a U.S. commercial utility to modernize their NPP control rooms.
\end{abstract}

Keywords: Ergonomic Safety \& Health, Nuclear Power Plants, Control Room Modernization, Digital Instrumentation \& Control Systems, Light Water Reactor Sustainability Program, Human Factors Engineering.

\section{Introduction: Why Modernize Nuclear Power Plant Control Rooms?}

Existing commercial nuclear power plants (NPPs) are valuable assets in the 
infrastructure portfolio of the United States (U.S.). They safely and reliably provide approximately $19 \%$ of all the electricity generated. While other non-carbon emitting renewable electrical generation technologies are making advances, their intermittency poses challenges to their large-scale integration into the grid. Indeed, historical analyses [1] have shown that previous energy transitions have taken decades, and so NPPs are still needed for the foreseeable future to generate base-load electricity.

The instrumentation and control (I\&C) systems in commercial NPPs are the "eyes and ears' of the operator, allowing them to control important primary and ancillary systems [2]. That is, NPP I\&C systems are important because they are the way in which the operators maintain good situation awareness, thereby allowing the plant to operate safely and efficiently for all phases of operation.

Given this need, upgrading the existing I\&C in commercial NPPs is very important because they potentially limit the operation of NPPs into their second license extension. Current NPP control room I\&C is comprised mostly of analog technologies, but in other energy sectors analog I\&C has largely been replaced with digital technologies. Thus, without the manufacturing and product support base for these legacy analog systems, spare and replacement parts are becoming increasingly scarce. As a result, analog systems, although still reliable, have reached the end of their useful service life.

Given the importance of I\&C systems in NPP main control rooms and the need to upgrade them, the U.S. Department of Energy (DOE) sponsors the Light Water Reactor Sustainability (LWRS) Program, which facilitates and encourages costshared collaborations with utilities to safely extend the life of currently operating commercial NPPs. The LWRS Program has a broad scope and includes human factors research and development (R\&D), human factors engineering (HFE), and ergonomics to support plant modernization, and in particular, control room I\&C modernization. The remainder of this paper describes the ergonomic safety and health R\&D and HFE performed in collaboration with multiple U.S. commercial utilities to modernize their NPP control rooms.

\section{Guidance for the Ergonomic and Human Factors Engineering Approach}

The U.S. Nuclear Regulatory Commission (NRC) closely regulates the U.S. civilian nuclear industry to protect people and the environment. The HFE and the ergonomics of the control room are within the purview of the NRC's oversight, and so utilities leverage NRC guidance on human factors such as NUREG-0711 [3] and NUREG0700 [4], as well as industry guidance developed by the Electric Power Research Institute (EPRI) [5] and Idaho National Laboratory (INL) [6] when engaging in control room modernization. Having a common regulatory HFE program review model and established industry guidance allows for a level of standardization in the approach taken to conduct HFE R\&D for control room modernization. 


\section{Recent Ergonomic Activities for Control Room Modernization}

In 2016, a collaboration started that involved performing cost-shared R\&D activities with a U.S. nuclear utility on control room modernization at four of its commercial NPPs. The purpose of this project was to conduct R\&D to ensure these NPPs are able to operate for beyond their original licensing period with new and/or revitalized technologies. Additionally, this R\&D project needed to consider the differences that must be addressed in fleet settings and in unregulated (i.e., deregulated or merchant) markets where different decision factors weigh on investment decisions and to demonstrate methods and techniques for modernization and investment in NPPs in these settings.

The utility partner was in the process of upgrading the non-safety related (NSR) nuclear steam supply systems (NSSS) and balance of plant (BOP) systems for four commercial NPP units. Although the utility had properly maintained and upgraded the NSR NSSS and BOP systems with like-for-like replacement parts, the systems had been in service for more than 30 years, and upgrading them to a new digital I\&C system presented an opportunity to improve equipment reliability, reduce the likelihood of plant transients, and in general improve safety margins. For this upgrade, the changes to the control room included: 1) the addition of soft controls and digital control system (DCS) based alarm points on video display units added to the control boards, 2) the deletion of a number of analog controls and indicators, and 3) changes to procedures, the conduct of operations, and training. Given these changes, this work focused on the effects a hybrid human system interface (HSI) could have on the safety and health ergonomics of the control room, including issues such as: changes and inconsistencies in HSI design and operation, and impacts on operator workload, situation awareness, and the conduct of operations.

At the beginning of the project, a number of technical HFE R\&D activities for control room modernization were performed. The focus was on performing ergonomic and other HFE technical analyses of digital I\&C system hardware that was going to be installed, and in particular, the DCS's HSI.

Figure 1 shows the results of ergonomic and HFE analyses of the I\&C hardware and evaluations of the DCS's HSI. Using state-of-the-art, three-dimensional modeling, researchers were able to identify that physical placement of touch screen monitors on the control boards was beyond the reach of some operators and that other aspects of their design (e.g., font size) and placement (e.g., viewing angle) affected screen legibility because they were not designed in a manner that is consistent with HFE design recommendations. 


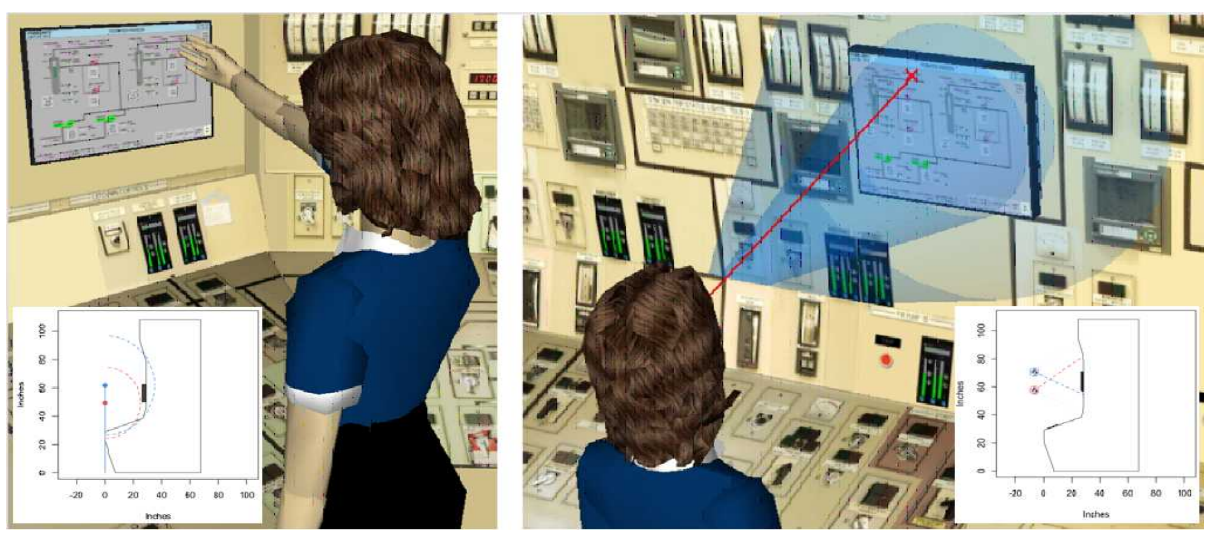

Fig. 1. Ergonomic and HFE evaluations using three-dimensional modeling help identify and prevent the introduction of new human error traps when performing digital I\&C upgrades.

\section{Ergonomic and Human Factors Simulator-Based R\&D Activities}

The latter stages of the project involved conducting operator-in-the-loop studies at the utility's control room simulators. The purpose of the workshops was to conduct HFE validation assessments of the planned control room I\&C upgrades for the four NPP units, and had the objective of identifying potential HFE issues with the upgrades prior to installation in the main control room.

The operator-in-the-loop workshops entailed direct observations and assessments of key operator interactions with the existing and new HSIs across a number of normal, abnormal, and emergency scenarios. The scenarios were designed to evaluate the functional ergonomic and human factors aspects of the existing and upgraded I\&C systems, with particular emphasis on the ability of the new I\&C system to support operators' cognitive processes and their ability to facilitate the operators' ability to perform the correct control actions. The general workshop flow is depicted in Figure 2.

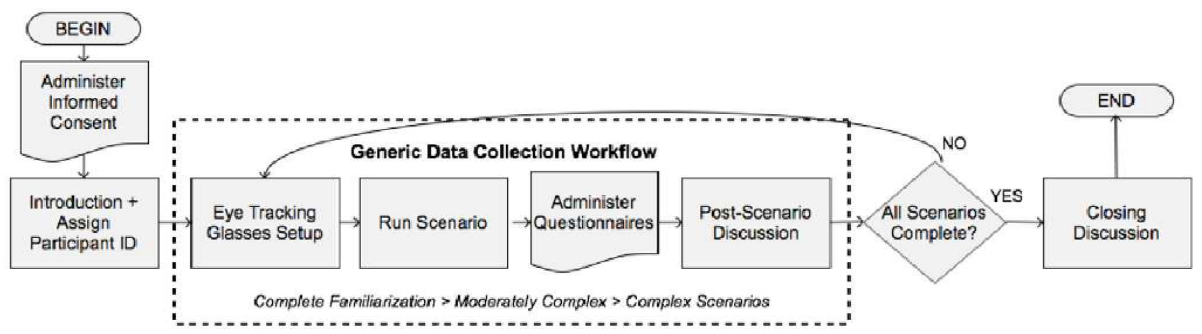

Fig. 2. Workshop execution workflow.

The assessment strategy focused on assessing plant safety and overall human- 
system performance. As such, measures of usability, workload, and situation awareness were collected during select scenarios to evaluate the suitability of the new HSIs in an operational context. During each scenario, the evaluation team also identified key information that determined the success or failure of the new HSIs as installed.

Human factors researchers and operationally experienced monitors observed the operators who performed actions in the scenarios using relevant procedures (see Figure 3 and Figure 4). Observations focused on operator interactions that were affected by the upgraded controls and indicators. Changes in time available for operator action, as well as information availability, were identified by observers during the scenarios.

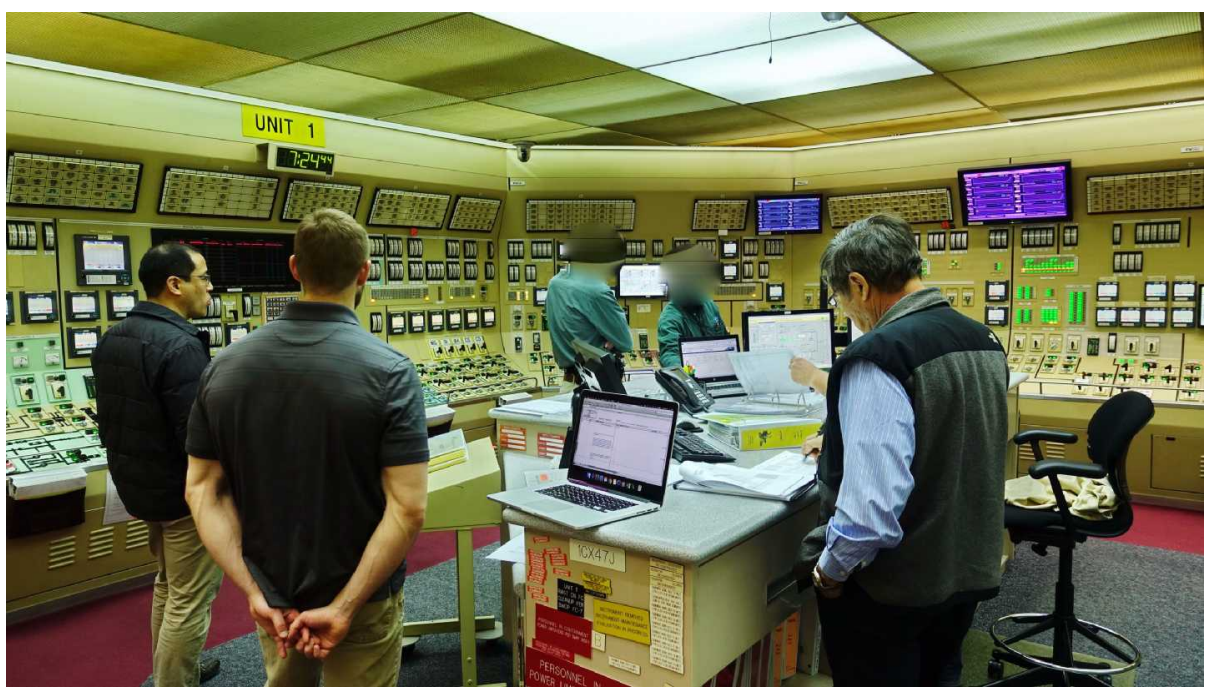

Fig. 3. Ergonomics researchers observing NPP operators. 


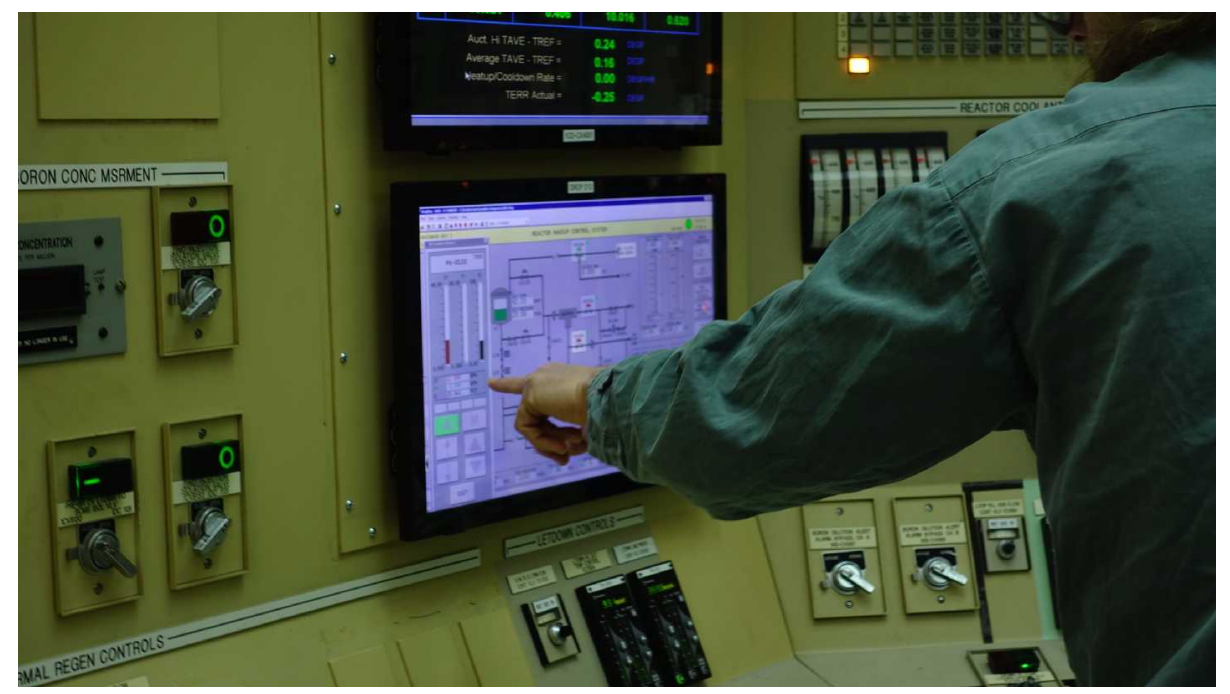

Fig. 4. NPP operator interacting with the new DCS HSI.

\subsection{Workshop Results}

If any potential performance deviations or difficulties were identified, then the LWRS HFE project team held a post-scenario discussion with the operators to identify potential contributors (e.g., HMI design issue(s), procedure issue(s), training/experience, simulator artifacts, etc.) so that appropriate actions could be taken. This assessment, attribution, and disposition process is shown in Figure 5.

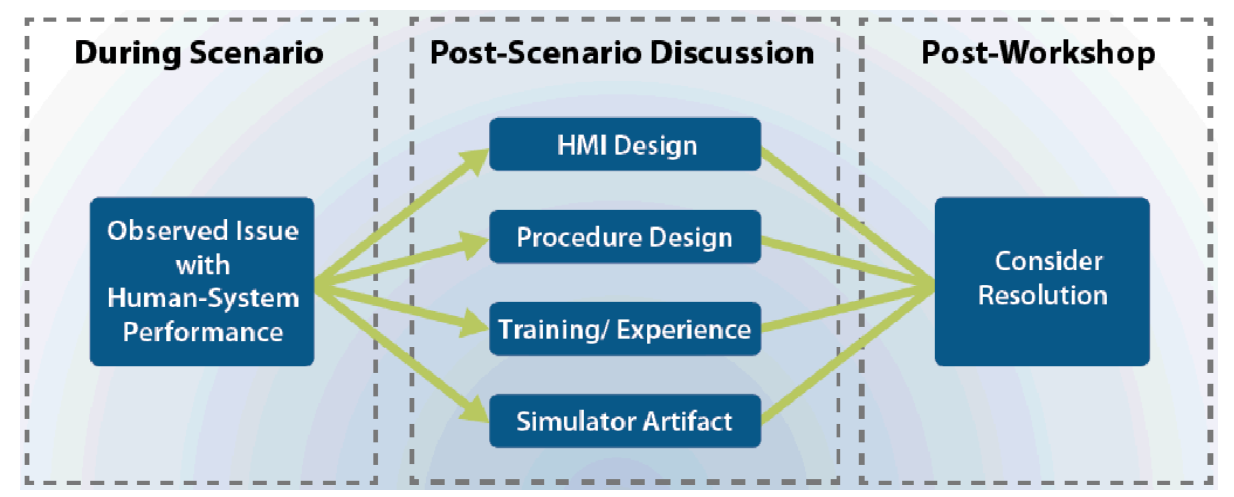

Fig. 5. Ergonomics and HFE Assessment Strategy.

The results of the operator-in-the-loop workshop showed that the upgraded HSIs support operators in emergency operation tasks in that they did not adversely affect operator performance in highly complex scenarios where the operators' responses to transients and casualties that challenge the safety of the plant are important. Operators were also able to complete tasks without losing global situation awareness. This result 
indicated that the upgrades do not adversely affect the operators' mental models of the plant, particularly with respect to their ability to perform their critical safetyrelated actions.

For normal and abnormal operating conditions, the operators were able to successfully complete the tasks correctly, completely, and without confusion or misunderstanding using the upgraded HSIs. The operators were sufficiently alerted, provided with usable controls, and received adequate feedback from the HSIs.

The results also showed a number of operational improvements that will be realized with the successful installation of the new DCS. The most apparent example of this is in how the DCS automatically swaps controlling channels through a median select control function instead of manual channel selector switches, which therefore eliminates any potential operator errors in failing to correctly diagnose that a transmitter or sensor has failed. In addition, the new HSIs were well designed and presented more critical plant parameters in a user-friendly manner to the operators, which facilitated their ability to get a big picture understanding of the plant's state. This was most apparent in scenarios where operators had to detect, diagnose, and mitigate small leaks in the reactor coolant system. Observations and analyses of the scenarios identified a few medium and low level human factors issues, but the performance issues observed can and will be addressed satisfactorily with training and revised procedures. Overall, in the context of evaluating human-system performance, the control room operators appear to be sufficiently supported by upgraded HSIs, operating procedures, and their training to safely control the plant with the upgraded DCS.

\section{$5 \quad$ Additional Work Performed}

LWRS program researchers also developed frameworks for an HFE program management plan and a business case for fleet-based control room modernization. This work was done because it is recognized that control room modernization is the convergence of scientific, engineering, and economic considerations [7]. The HFE program plan provides structured and systematic guidance on an upgrade process that goes beyond obsolescence management. It defines an endpoint design concept for a fully modernized control room and a migration strategy for describing the phasing and ordering of I\&C and control board changes. By considering main control room improvements that produce harvestable cost savings, the business case analysis allows utilities to move beyond performing like-for-like replacements that historically have not reduced operations and maintenance costs. The development of an HFE program plan and business case are additional activities that help utilities to achieve their longterm sustainability goals.

\section{Conclusion}

In summary, LWRS program researchers conducted cutting-edge R\&D that furthered DOE's objective to support the long-term sustainability of the light water reactor fleet 
by ensuring the human factors aspects of control room upgrades are addressed. By performing R\&D that addresses reliability and obsolescence issues of legacy analog control rooms, and by demonstrating and documenting the human factors processes that utilities should undertake to perform control room modernization for a fleet of NPPs operating in a merchant market, this work provides the technical bases that help reduce the uncertainty and risk of modernizing control rooms, thereby helping provide the incentives for the industry to make investments required for nuclear power operation periods to 60 years and beyond.

\section{Disclaimer}

INL is a multi-program laboratory operated by Battelle Energy Alliance LLC, for the United States Department of Energy under Contract DE-AC07-05ID14517. This work of authorship was prepared as an account of work sponsored by an agency of the United States Government. Neither the United States Government, nor any agency thereof, nor any of their employees makes any warranty, express or implied, or assumes any legal liability or responsibility for the accuracy, completeness, or usefulness of any information, apparatus, product, or process disclosed, or represents that its use would not infringe privately-owned rights. The United States Government retains, and the publisher, by accepting the article for publication, acknowledges that the United States Government retains a nonexclusive, paid-up, irrevocable, worldwide license to publish or reproduce the published form of this manuscript, or allow others to do so, for United States Government purposes. The views and opinions of authors expressed herein do not necessarily state or reflect those of the United States government or any agency thereof. The INL issued document number for this paper is: INL/CON-18-45643.

\section{References}

1. Smil, V.: Energy Transitions: History, Requirements, Prospects. ABC-CLIO, LLC. Santa Barbara, CA (2010).

2. International Atomic Energy Agency: Modern Instrumentation and Control for Nuclear Power Plants: A Guidebook, IAEA Technical Report Series \#387, Vienna, Austria (1999).

3. U.S. Nuclear Regulatory Commission: Human Factors Engineering Program Review Model, NUREG-0711 (Rev. 3), Washington, DC (2012).

4. U.S. Nuclear Regulatory Commission: Human-system interface design review guidelines, NUREG-0700 (Rev. 2), Washington, DC (2002).

5. Electric Power Research Institute: Human Factors Guidance for Control Room and Digital Human-System Interface Design and Modification: Guidelines for Planning, Specification, Design, Licensing, Implementation, Training, Operation, and Maintenance for Operating Plants and New Builds. EPRI TR 3002004310, Palo Alto, CA (2015).

6. Boring, R.L., Ulrich, T., Joe, J.C., Lew, R.: Guideline for Operational Nuclear Usability and Knowledge Elicitation (GONUKE). Procedia Manufacturing, 3, 1327-1334 (2015).

7. Joe, J.C.: A Human Factors Meta Model for U.S. Nuclear Power Plant Control Room 
Modernization. Proceedings of the $10^{\text {th }}$ International Topical Meeting on Nuclear Plant Instrumentation, Control, and Human-Machine Interface Technologies (NPIC \& HMIT 2017), 1833-1842, San Francisco, CA (2017). 